\title{
Calcium and vitamin D reduced non-vertebral fractures and bone loss in the elderly
}

\author{
Dawson-Hughes B, Harris SS, Krall EA, et al. Effect of calcium and vitamin D supplementation on bone density in men and women \\ 65 years of age or older. N Engl J Med 1997 Sep 4;337:670-6.
}

\section{Objective}

To assess the effectiveness of combined oral calcium and vitamin D supplementation in reducing non-vertebral fractures and bone loss in elderly people living in the community.

\section{Design}

3 year randomised, double blind, placebo controlled trial.

\section{Setting}

Community based study in the USA.

\section{Participants}

445 healthy people living in the community who were $\geqslant 65$ years of age (55\% women) were enrolled and 389 (mean age 71 y) were included in the intention to treat analysis. Exclusion criteria were current cancer or hyperparathyroidism; a kidney stone in the past 5 years; renal disease; bilateral hip surgery; bisphosphonate, calcitonin, oestrogen, tamoxifen, or testosterone use in the past 6 months; fluoride use in the past 2 years; low femoral neck bone mineral density; dietary calcium intake exceeding $1500 \mathrm{mg}$ per day; and laboratory evidence of kidney or liver disease. Follow up was $87 \%$.

\section{Intervention}

Participants, stratified by sex, race, and decade of age, were assigned to elemental calcium (calcium citrate malate), 500 $\mathrm{mg} /$ day, and vitamin $\mathrm{D}$ (cholecalciferol), $700 \mathrm{IU} /$ day, or to placebo. Participants maintained their usual diet during the trial. Intention to treat analysis included 187 participants allocated to calcium and vitamin D and 202 participants allocated to placebo.

\section{Main outcome measures}

Non-vertebral fractures verified by radiographs or hospital records, and bone mineral density at the femoral neck, spine, and total body measured every 6 months.

\begin{abstract}
Main results
Among all participants, $\geqslant 1$ non-vertebral fracture occurred in 11 participants $(5.9 \%)$ who received calcium and vitamin $\mathrm{D}$ and in 26 participants $(12.9 \%)$ who received placebo $(p=0.02)$ (table). Of these 37 participants (32 women), 28 had osteoporotic fractures. Intention to treat analysis showed more bone loss in the placebo group compared with the calcium and vitamin $\mathrm{D}$ group at the total body $(\mathrm{p}<0.001)$, femoral neck $(p=0.02)$, and spine $(p=0.04)$ at 3 years. Active treatment analysis showed increases in bone mineral density in the calcium and vitamin D group at all sites at 1 year $(p \leqslant 0.05$ for all comparisons), but only increases in total body bone mineral densitiy at 3 years $(\mathrm{p}<0.001)$.
\end{abstract}

\section{Conclusion}

Calcium and vitamin D supplementation decreased the risk of non-vertebral fractures and moderately reduced bone loss in elderly people living in the community.

Calcium and vitamin D v placebo*

\begin{tabular}{llllll}
\hline $\begin{array}{l}\text { Outcome at } \\
\text { 3years }\end{array}$ & $\begin{array}{l}\text { Calcium and } \\
\text { vitamin D } \\
\text { EER }\end{array}$ & $\begin{array}{l}\text { Placebo } \\
\text { CER }\end{array}$ & $\begin{array}{l}\text { RRR } \\
(95 \% \text { CI) }\end{array}$ & $\begin{array}{l}\text { ARR } \\
\mid E E R- \\
\text { CER } \mid\end{array}$ & $\begin{array}{l}\text { NNT } \\
\text { (CI) }\end{array}$ \\
\hline $\begin{array}{l}\text { Non-vertebral } \\
\text { fracture }\end{array}$ & $5.9 \%$ & $12.9 \%$ & $\begin{array}{l}54.3 \% \\
(12 \text { to } 77)\end{array}$ & $7.0 \%$ & $\begin{array}{l}15 \\
(8 \text { to 12) }\end{array}$ \\
\hline
\end{tabular}

*Abbreviations in table defined in glossary; RRR, ARR, NNT, and CI calculated from data in article.

Sources of funding: National Institutes of Health and the Jean Mayer US Department of Agriculture Human Nutrition Research Center on Aging, Tufts University.

For article reprint:Dr B Dawson-Hughes, Jean Maver US Department of Agriculture Human Nutrition Research Center on Aging, Tufts University, 711 Washington Sreet, Boston, MA 02111, USA.

Adapted from an abstract published in ACP Journal Club 1998 Mar-Apr;128:44.

\section{Commentary}

The study by Dawson-Hughes et al contributes to the growing evidence that older people can benefit from the correction of calcium imbalance. The study is particularly useful because it shows that after taking oral supplements for a period of only 1 year, bone density can increase; however, with intake at the usual dietary levels, bone density loss will continue. A similar study and 2 reviews support these findings. ${ }^{1-3}$ One review points to the need for an economic evaluation, which the current study did not conduct. ${ }^{2}$

The participants in the study were all healthy and mobile older people living independently in the community, who were advised to continue with their usual diet. The study did not describe in detail variability in the participants' usual diets and did not include participants with a range of abnormal conditions often found in older people.

The findings from the study are useful for nurses working with older people, particularly in community care settings such as nursing homes, those working in orthopaedics, and clinical nurse specialists in nutritional care. The findings from the study add to our knowledge about the importance of nutritional assessment for older people. Nutritional problems are not only associated with increased mortality and morbidity but also with poor quality of life, for example reduced personal confidence and decreased mobility resulting from falls and fractures.
Jan Dewing, RGN, MN, RNT Project Worker for Community Hospital Oxfordshire Community Health NHS Trust Royal College of Nursing Institute Oxford, $U K$

1 Chapuy MC, Arlot ME, Duboeuf F, et al. Vitamin D3 and calcium to prevent hip Vitamin D3 and calcium to prevent hip
fractures in elderly women. $N$ Engl $J$ Med

2 Gillespie WJ, Henry DA, O'Connell DL, et al. Vitamin D and vitamin D analogues in the prevention of fractures in involutional and post-menopausal osteoporosis. In: the Cochrane Library [database on disk and CDROM]. The Cochrane Collaboration; issue 4. Oxford: Update Software, 1997.

3 Marshall D, Johnell O, Wedel H. Meta-analysis of how well measures of bone mineral density predict occurrence of osteoporotic fractures. BMJ 1996;312:1254-9. 